\title{
Laparoskopik Kolesistektomi Operasyonlarında Basınç Kontrollü ve Volüm Kontrollü Ventilasyon Modlarının Karşılaştırılması
}

\section{Comparison of Pressure-Controlled Ventilation and Volume-Controlled Ventilation During Laparoscopic Cholecystectomy}

\author{
Öznur Şen, Ferda Yılmaz İnal, Mehmet Toptaş, Nurdan Aydın, Nevzat Cem Sayılgan*, \\ Ayşe Çiğdem Tütüncü* ${ }^{*}$ Aytül Taş, Fatime Nayman, Ecder Özenç \\ S. B. Haseki Eğitim ve Araştırma Hastanesi, Anesteziyoloji ve Reanimasyon Kliniği, Istanbul, Türkiye \\ *istanbul Üniversitesi Cerrahpaşa Tıp Fakültesi, Anesteziyoloji ve Reanimasyon Anabilim Dalı, İstanbul, Türkiye
}

\section{Özet}

\begin{abstract}
Amaç: Ocak 2011-Ocak 2013 tarihleri arasında gerçekleştirilen laparoskopik kolesistektomi operasyonları sırasında uygulanan Basınç Kontrollü ve Volüm Kontrollü Ventilasyon modlarının hemodinami, solunum mekanikleri ve oksijenizasyona olan etkilerinin anestezi kayıt formlarındaki verileri kullanarak retrospektif analizi amaçlanmıştır.

Yöntemler: Retrospektif olarak hasta dosyaları, preoperatif, intraoperatif ve postoperatif anestezi kayıt formları taranarak yapılan çalışmada, Basınç Kontrole Ventilasyon (BKV) modu ile tidal volümü 8-9 mLkg-1 tidal volüm oluşturacak basınç desteği, 12 soluk/dak ve $5 \mathrm{~cm} \mathrm{H} \mathrm{H}_{2} \mathrm{O}$ ile ventile edilmiş olgular Grup $1(\mathrm{n}=41)$, Volüm Kontrole Ventilasyon (VKV) ile 8-9 mLkg-1 tidal volüm, 12 soluk/dak ve $5 \mathrm{~cm} \mathrm{H}_{2} \mathrm{O}$ ile ventile edilmiş olgular Grup $2(n=41)$ olarak kaydedildi. Hemodinamik ve solunum mekanikleri, preoperatif dönem, entübasyondan sonrası supin pozisyonunda, $\mathrm{CO}_{2}$ insuflasyonundan 15$20 \mathrm{dk}$ sonra, desuflasyondan sonra kaydedilmiş parametreler kullanıldı. Aynı dönemlerde ve postoperatif değerlendirilmiş arter kan gazı (AKG) analizleri de kaydedildi.
\end{abstract}

Bulgular: Grup 2'nin insuflasyon dönemi sistolik arter basınç (SAB) değerleri, grup 1'e göre yüksek bulundu. $\mathrm{EtCO}_{2}$ değerleri açısından gruplar arasında fark yoktu. Grup 2'nin tüm dönemlerdeki $P_{\text {peak }}$ değerleri, insuflasyon dönemi $P_{\text {plato }}$ değerleri, grup 1'e göre yüksekti. Grup 2'nin tüm dönemlerdeki kompliyans değerleri, grup 1'e göre düşük, desuflasyon dönemi Vd/Vt değerleri ise yüksek bulundu. Grup 2 'nin postoperatif derlenme dönemi $\mathrm{PaO}_{2}$ değerleri, grup 1'e göre düşük, supin dönem $\mathrm{Vd} / \mathrm{Vt}$ değerleri ise yüksek bulundu.

Sonuç: Basınç kontrollü ventilasyon, laparoskopik kolesistektomilerde pnömoperitonyumun neden olabileceği olumsuzlukları engelleme ve düzeltmede, volüm kontrollü ventilasyona alternatif olarak kullanılabileceğini düşünmekteyiz. (Haseki Tıp Bülteni 2014; 52: 75-9)

Anahtar Sözcükler: Basınç kontrollü ventilasyon, volüm kontrollü ventilasyon, hemodinami, solunum mekanikleri, oksijenizasyon

\begin{abstract}
Aim: The study aimed to carry out a retrospective analysis of the effects of pressure-controlled and volume-controlled ventilation during laparoscopic cholecystectomy procedures performed between January 2011 and January 2013 on hemodynamics, respiratory mechanics and oxygenation.

Methods: Data were mainly obtained from preoperative and intraoperative anaesthetic record files. Eighty-two patients, who had undergone laparoscopic cholecystectomy, were retrospectively studied. Group $1 \quad(n=41)$ received pressure support for obtaining 8-9 $\mathrm{mLkg}-1$ tidal volume with pressurecontrolled ventilation, group $2(n=41)$ received volume-controlled ventilation with a tidal volume of $8-9 \mathrm{mLkg}-1$, a respiratory rate of 12 breaths/min and a positive end-expiratory pressure (PEEP) of $5 \mathrm{~cm} \mathrm{H}_{2} \mathrm{O}$. Hemodynamic and respiratory parameters, which were measured preoperatively, after intubation in the supine position, 15 minutes after $\mathrm{CO}_{2}$ insufflation, and after desufflation, were recorded. Arterial blood gas analyses were recorded which were measured at the same time with hemodynamics and respiratory parameters and during the postanesthetic care period.
\end{abstract}

Results: Systolic arterial pressure at the time of insufflation was higher in Group 2 than in group 1. There was no difference in $\mathrm{EtCO}_{2}$ levels between the groups. All times Ppeak and insufflation time Pplato levels were higher in group 2. Compliance at all periods was lower in group 2. Desufflation period $\mathrm{Vd} / \mathrm{Vt}$ and $\mathrm{P}(\mathrm{A}-\mathrm{a}) \mathrm{O}_{2}$ levels were higher in group 2. Post anaesthetic care $\mathrm{PaO}_{2}$ levels were higher in group 1.

Conclusion: Pressure-controlled ventilation can be an alternative to volume-controlled ventilation during general anaesthesia to prevent and repair pneumoperitonium-related side-effects during laparoscopic cholecystectomy. (The Medical Bulletin of Haseki 2014; 52: 75-9)

Key Words: Pressure-controlled ventilation, volume-controlled ventilation, hemodynamics and respiratory mechanics, oxygenation
Yazışma Adresi/Address for Correspondence: Öznur Şen

S. B. Haseki Eğitim ve Araştırma Hastanesi, Anesteziyoloji ve Reanimasyon Kliniği, istanbul, Türkiye Tel.: +90 5324927763 E-posta: senoznur@gmail.com

Geliş Tarihi/Received: 29 Mayıs 2013 Kabul Tarihi/Accepted: 25 Eylül 2013
Haseki Tıp Bülteni,

Galenos Yayınevi tarafından basılmıștır.

The Medical Bulletin of Haseki Training and Research Hospital, published by Galenos Publishing. 


\section{Giriş}

Laparoskopik cerrahi, hastaların hastanede kalış sürelerinin daha kısa olması, insizyon alanının daha küçük olması, postoperatif ağrının daha az olması, erken mobilizasyon sağlaması, postoperatif dönemde pulmoner fonksiyonlarda daha az bozulma görülmesi, ve insizyon yerinde nedbe izinin daha az olması gibi nedenlerle tercih edilmektedir $(1,2)$.

Laparoskopik cerrahi süresince kardiopulmoner ve metabolik değişikliklerin patofizyolojisi kompleks olup, bazı mekanik ve nörohümoral mekanizmalar ile bağlantılı olabilmektedir. Bunların başında da, $\mathrm{PaCO}_{2}$ değişiklikleri, pnömoperitoneum süresi, intraabdominal basınç artışı, altta yatan hastalıklar, hasta pozisyonu ve ventilasyon modu gelmektedir $(3,4)$.

Volüm kontrollü ventilasyon (VKV), kare akım paterni ile anestezi sırasında kullanılan geleneksel ventilasyon modudur. Basınç kontrollü ventilasyon (BKV) ise yoğun bakım ünitelerindeki hipoksik hastalarda özellikle acute Akut Sıkıntılı Solunum sendromu'nda (ARDS) gaz değişimini düzelttiği öne sürülen alternatif bir ventilasyon modudur (5). Basınç kontrollü ventilasyonda alveoller ve proksimal hava yolları arasındaki basınç farkının en fazla olduğu dönem inspiryumun başlangıcındadır. Böylelikle tidal volümün büyük kısmı erken inspiryumda fazında alveollere dolarak anstabil alveollerin açık kalmasını kolaylaştııı (6). Ayrıca basınç kontrollü ventilasyonun aynı tidal volüm ve aynı inspiryum zamanlı volüm kontrollü ventilasyona göre daha yüksek ortalama havayolu basıncına sahip olduğu için oksijenasyonu daha iyi sağladığı belirtilmektedir $(7,8)$. Yani inspiryum basıncını sabit tutarak kısa zaman sabiteli alveolden uzun zaman sabiteli alveole tidal volümün dağılımını düzenler ve ventilasyonun heterojenitesini azaltarak arteriyel oksijenasyonu arttıır (6).

Laparoskopik kolesistektomi ameliyatlarında pneumoperitoneum; intraabdominal basıncın yükselmesine, akciğer volümlerinin ve fonksiyonel rezidüel kapasitenin azalmasına, pulmoner kompliyansın düşmesine, buna karşın hava yolu direncinin artmasına, diyafragmanın itilmesine, akciğer bazal kısımlarının atalektazisine, hidrostatik güçlerin redistribüsyonuna ve ventilasyon-perfüzyon bozukluğuna yol açar $(3,4)$.

Bu çalışmada, laparoskopik kolesistektomi uygulanan hastalarda BKV ile VKV modlarının hemodinami, solunum mekaniği ve oksijenizasyona etkilerini karşılaştırmayı amaçladık.

\section{Yöntemler}

Çalışma, retrospektif olarak Ocak 2011-Ocak 2013 yılları arasında laparoskopik kolesistektomi operasyonu geçirmiş olguların dosyaları, preoperatif, intraopreatif ve postoperatif verileri taranarak gerçekleştirildi. Çalışmaya
ASA 1-2 grubu, 18-70 yaş arası, kaydedilen kardiyak, pulmoner, hepatorenal, nöromüsküler hastalığı olmayan, toraks operasyonu geçirmemiş olgular dahil edildi. Standart anestezi indüksiyonu yapılmış, $\% 50 \mathrm{O}_{2}$ /hava, 12 soluk/dk, $5 \mathrm{~cm} \mathrm{H} \mathrm{H}_{2} \mathrm{O}$ PEEP ve $2 \mathrm{~L} / \mathrm{dk}$ akım uygulanan, BKV modu ile 8-9 mLkg-1 tidal volüm sağlayan basınç desteği ile ventile edilmiş olgular Grup 1 ( $n=41)$, VKV modu ile 8-9 mLkg-1 tidal volüm ile ventile edilmiş olgularda Grup 2 $(n=41)$ olarak kaydedildi.

Hemodinamik parametreler (SAB: sistolik arter basıncI, DAB: diastolik arter basıncı, OAB: ortalama arter basıncı, $\mathrm{KAH}$ : kalp atım hızı) ve solunum mekanikleri $\left(\mathrm{P}_{\text {peak }}, \mathrm{P}_{\text {plato, }}\right.$ $P_{\text {ortalama, }} \mathrm{C}$ : kompliyans, $\mathrm{E}_{\mathrm{TCO} 2}$ ) ölçümlerinden entübasyon sonrası supin pozisyonunda, $\mathrm{CO}_{2}$ insuflasyonundan $15 \mathrm{dk}$ sonra ve desuflasyondan $10 \mathrm{dk}$ sonra yapılmış ölçümler kaydedildi. Bu ölçümlerle eş zamanlı ve postoperatif derlenme sırasında değerlendirilen AKG analizleri kaydedildi. Kaydedilen verilerle $\mathrm{Vd} / \mathrm{Vt}$ ve $\mathrm{P}(\mathrm{A}-\mathrm{a}) \mathrm{O}_{2}$ değerleri hesaplandı.

İstatistiksel analiz için SPSS 15.0 for Windows programı kullanıldı. Tanımlayıcı istatistikler; kategorik değişkenler için sayı ve yüzde, sayısal değişkenler için ortalama, standart sapma olarak verildi. Sayısal değişkenlerin iki grup karşılaştırmaları normal dağılım koşulu sağlandığı durumda Student t testi, normal dağılım koşulu sağlanamadığı durumlarda Mann Whitney $U$ testi ile yapıldı. Sayısal değişkenlerin takip verileri Tekrarlı ölçüm Varyans Analizi ile test edildi. Kategorik değişkenlerin oranları Ki kare testi ile analiz edildi. İstatistiksel anlamlılık düzeyi $p$ değerinin 0,05'ten küçük olması durumu olarak kabul edildi.

\section{Bulgular}

Demografik veriler açısından gruplar arasında fark yoktu (Tablo 1). Hemodinamik parametrelere baktığımızda, grup 2'nin $\mathrm{CO}_{2}$ insuflasyon dönemi SAB değerleri, grup 1'e göre yüksek bulundu $(p<0,001)$ (Grafik 1). Gruplar arasında $K A H, D A B$ ve OAB değerleri açısından fark bulunmadı.

Solunum mekaniklerini değerlendirdiğimizde, grup 2'nin entübasyon sonrası supin dönem, $\mathrm{CO}_{2}$ insuflasyon ve desuflasyon dönemi $P_{\text {peak }}$ değerleri, grup 1'e göre yüksek bulundu ( $<<0,01, p<0,001, p<0,001)$ (Grafik 2). Grup 2'nin insuflasyon dönemi Pplato değerleri, grup 1'e göre yüksekti $(p<0,01)$ (Grafik 3 ). Portalama ve $\mathrm{Et}_{\mathrm{CO} 2}$ değerleri açısından gruplar arasında fark yoktu. Grup 2'nin tüm dönemlerdeki kompliyans değerleri, grup 1'e göre düşüktü ( $p<0,001, p<0,01, p<0,001)$ (Grafik 4). Grup 2'nin desuflasyon dönemi $\mathrm{Vd} / \mathrm{Vt}$ oranı ve $\mathrm{P}(\mathrm{A}-\mathrm{a}) \mathrm{O}_{2}$ değerleri grup 1'e göre yüksekti $(p<0,05)$ (Grafik 5) (Grafik 6).

AKG değerlerine baktığımızda, gruplar arası pH ve $\mathrm{PaCO}_{2}$ değerleri açısından fark yoktu. Grup 2'nin postoperatif derlenme dönemi $\mathrm{PaO}_{2}$ değerleri, grup 1'e göre düşük bulundu $(p<0,05)$ (Grafik 7$)$. 
Tablo 1. Olguların genel özellikleri

\begin{tabular}{|c|c|c|c|c|}
\hline & & Volüm Kontrol $(n=41)$ & $\begin{array}{l}\text { Basınç Kontrol } \\
(n=41)\end{array}$ & $\mathbf{p}$ \\
\hline \multirow[t]{2}{*}{ Cinsiyet $n(\%)$} & Erkek & $10(24,4)$ & $14(34,1)$ & 0,332 \\
\hline & Kadın & $31(75,6)$ & $27(65,9)$ & \\
\hline \multicolumn{2}{|c|}{ Yaş (ay) Ort \pm SD } & $50,39 \pm 12,89$ & $47,68 \pm 11,42$ & 0,317 \\
\hline \multicolumn{2}{|c|}{ Boy $(\mathrm{cm})$ Ort \pm SD } & $161,37 \pm 7,92$ & $162,15 \pm 8,84$ & 0,711 \\
\hline \multicolumn{2}{|c|}{ Kilo $(\mathrm{kg})$ Ort \pm SD } & $77,71 \pm 14,70$ & $78,63 \pm 13,13$ & 0,764 \\
\hline \multicolumn{2}{|c|}{ Operasyon süresi Ort \pm SD } & $72,80 \pm 17,80$ & $79,00 \pm 27,31$ & 0,724 \\
\hline
\end{tabular}

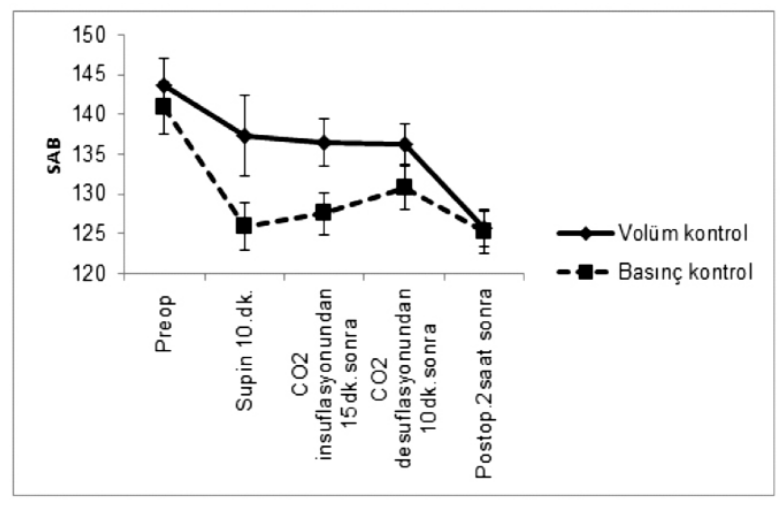

Grafik 1. Grupların SAB değerleri

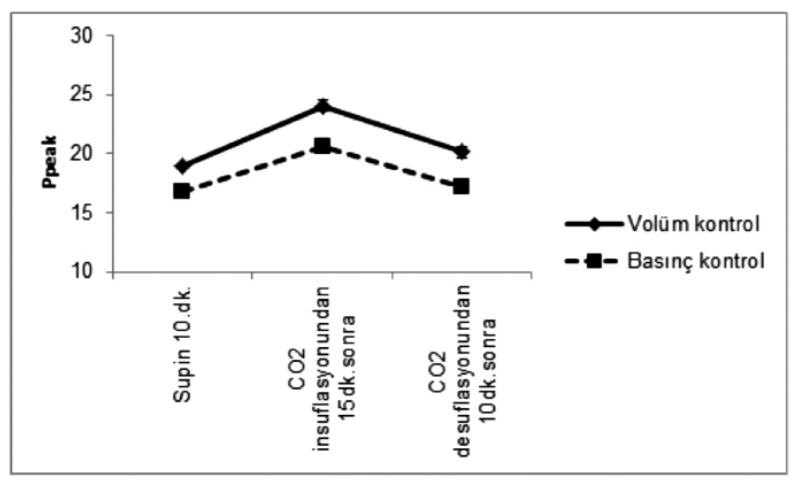

Grafik 2. Grupların $P_{\text {peak }}$ değerleri

\section{Tartışma}

Laparoskopik kolesistektomi ameliyatlarında pneumoperitoneum; intraabdominal basıncın yükselmesine, akciğer volümlerinin ve fonksiyonel rezidüel kapasitenin azalmasına, pulmoner kompliyansın düşmesine, buna karşın hava yolu direncinin artmasına, diyafragmanın itilmesine, akciğer bazal kısımlarında atalektazi gelişmesine, hidrostatik güçlerin redistribüsyonuna ve ventilasyon-perfüzyon bozukluğuna yol açmaktadır $(3,4)$.

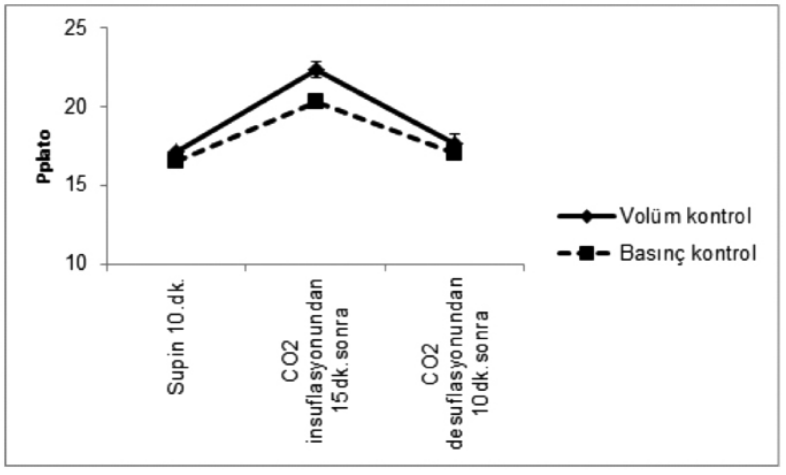

Grafik 3. Grupların P plato değerleri

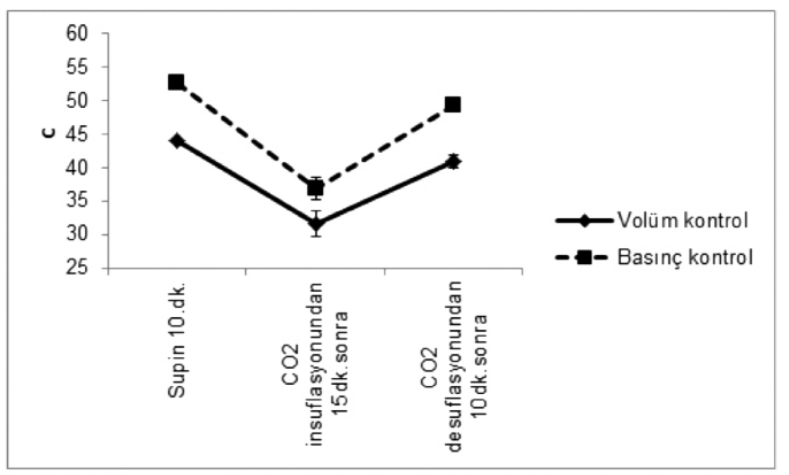

Grafik 4. Grupların C (kompliyans) değerleri

Volüm kontrollü ventilasyon, intraoperatif kullanılan en popüler moddur, fakat insuflasyon sırasında tepe havayolu basınçlarındaki artış nedeni ile tidal volüm ve solunum frekansında ayarlama yapılmasına ihtiyaç duyulabilir. Basınç kontrollü ventilasyon ise azalan inspiratuvar akım paterni ile hava yolu basınçlarında daha iyi kontrol sağlamasına rağmen, intraoperatif dönemde daha az kullanılan moddur.

Bu çalışmada, hemodinamik parametrelere baktığımızda insuflasyon dönemi SAB değerleri, VKV 


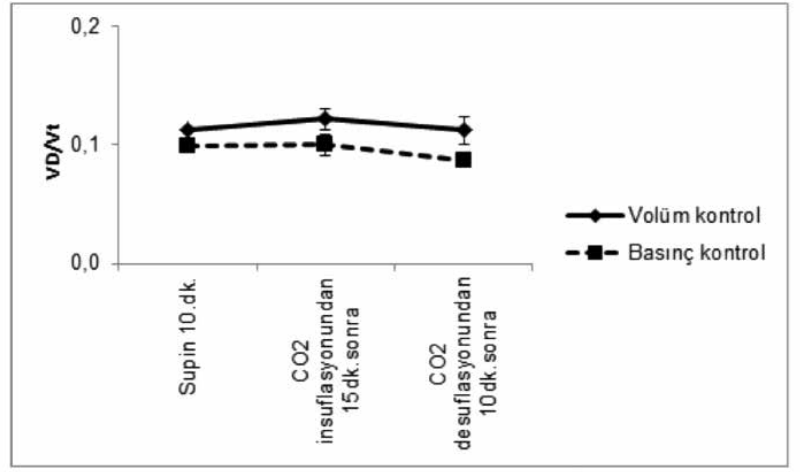

Grafik 5. Grupların Vd/Vt değerleri

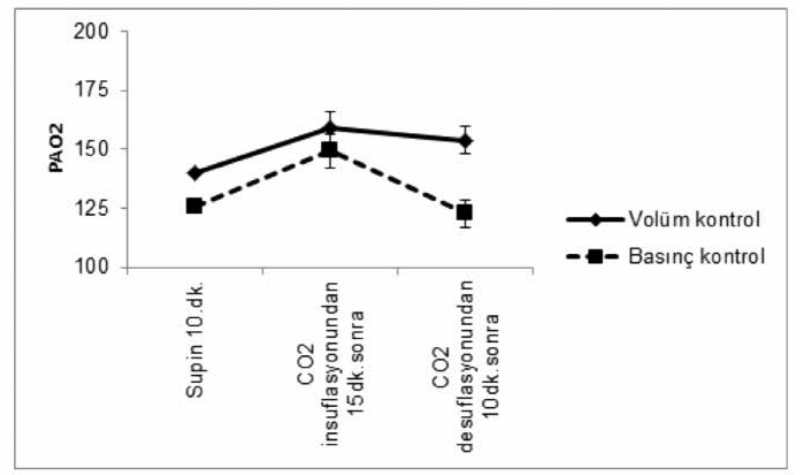

Grafik 6. Grupların $\mathrm{P}(\mathrm{A}-\mathrm{a}) \mathrm{O}_{2}$ değerleri

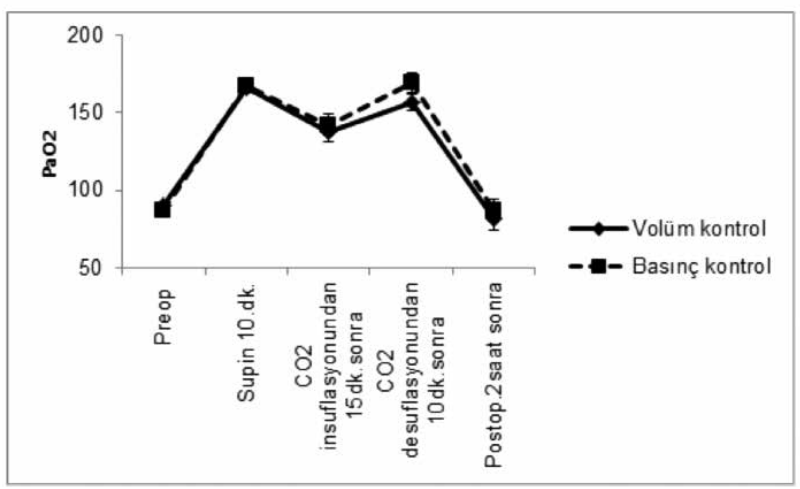

Grafik 7. Grupların $\mathrm{PO}_{2}$ değerleri

grubunda daha yüksek bulduk. Tyagi ve ark. (9) 42 olgu ile yaptıkları laporoskopik kolesistektomi vakalarına BKV ve VKV uyguladıkları çalışmada, hemodinamik açıdan gruplar arasında fark bulamamışlar. Gupta ve ark. (10) 102 laparoskopik kolesistektomi operasyonu geçiren obez olgu ile yaptıkları çalışmada, tüm olgulara pnömoperitonyum oluşturulduktan sonraki 15. dakikaya kadar VKV uygulamışlar, bu süreden sonra bir gruba VKV ile devam ederken, diğer gruba BKV uygulamışlar ve hemodinamik parametreler açısından gruplar arasında fark bulmamışlar. Balick-Weber ve ark. (11) 21 laparoskopik ürolojik girişim geçiren olgu ile yaptıkları çalışmada, pnömoperitonyum oluşturulduktan sonra 40 dakika tüm olguları VKV ile ventile edip, daha sonra BKV ile devam etmişler ve her iki modun, solunum mekaniğine, oksijenizasyona ve kardiyak fonksiyonlara etkisini transösofagiyal ekokardiyograf ile değerlendirmişler. Hemodinamik açıdan, kalbin sistolik ve diyastolik fonksiyonlarında gruplar arasında fark olmazken, $O A B^{\prime}$ nin VKV grubunda daha yüksek olduğunu bulmuşlar. Bununda pnömoperitonyum sırasında VKV uygulanırken, sol ventrikül sistol sonu duvar stresinin artmasına bağlı gelişebileceğini belirtmektedirler. Bizim çalışmamızda, insuflasyon döneminde SAB değerleri VKV modunda daha yüksek bulundu. Bu çalışmada ekokardiyografik inceleme yapılmamış olsa da, Ballick-Weber ve ark.'nın (11) çalışmasında bulunan sonuçlarla birlikte, insuflasyon ile birlikte olguların ters telendelenburg pozisyonuna alınması ve bu grupta $P_{\text {peak }}$ ve $P_{\text {plato }}$ değerlerininde yüksek seyretmesi ile plevral basıncın artması, pulmoner vasküler resistans ile birlikte sistemik vasküler rezistansın artmasına neden olduğunu düşünmekteyiz. Ayrıca değerler istatistiksel olarak yüksek bulunsa da fizyolojik sınırlar içinde seyretmekteydi.

Çalışmamızda, solunum mekanikleri ve oksijenizasyona baktığımızda BKV grubunda, pik havayolu basınçları daha düşük, kompliyans ve oksijenizasyonun daha yüksek, şant ve ölü boşluğun daha düşük olduğunu gördük. Tyagi ve ark. (9) peroperatif $\mathrm{PaO}_{2}$ ve $\mathrm{E}_{\mathrm{tCO}}$ değerlerinde gruplar arasında anlamlı fark bulmazken, BKV grubunun $P_{\text {peak }}$ değerleri, VKV grubuna göre daha düşük, entübasyon sonrası dönemde kompliyans değerlerini ise daha yüksek bulmuşlar. Gupta ve ark. (10) çalışmasında da BKV grubunda $\mathrm{P}_{\text {peak }}$ değerlerinin daha düşük, $\mathrm{PaO}_{2}$ 'nin daha yüksek, $\mathrm{P}(\mathrm{A}-\mathrm{a}) \mathrm{O}_{2}$ 'nin daha düşük olduğu bulunmuş. BalickWeber ve ark. (11) çalışmasında, VKV'den BKV'ye geçişte $P_{\text {peak }}$ değerlerinde anlamlı düşüş, dinamik kompliyansta da anlamlı artış olduğunu bulmuşlar. Fakat oksijenizasyonda, kalbin sistolik ve diyastolik fonksiyonlarında anlamlı değişiklik görülmemiş. Aynı şekilde Oğurlu ve ark. (12) 60 laparoskopik jinekolojik operasyon geçiren olgu ile yapılan çalışmada, $P_{\text {peak }}, P_{\text {plato, }} P_{\text {mean }}$ değerleri tüm dönemlerde BKV grunda daha düşük, kompliyans değerleri ise anlamlı derecede yüksek bulunmuş. Çalışmalarla da uyumlu olarak bizim çalışmamızda da, entübasyon sonrası, insuflasyon dönemi ve desuflasyon dönemi $P_{\text {peak }}$ değerleri ve insuflasyon dönemi $P_{\text {plato }}$ değerleri, BKV grubunda daha düşüktü. İki grup arasında $P_{\text {peak }}$ değerlerinin farklı olmasını, ventilasyon modları arasındaki farklı akım 
paternine bağlamaktayız, BKV modunda azalan akım paterni ve buna bağlı olarak da akım rezistansının daha erken dağılması basıncın düşük olmasını sağlamaktadır.

Çalışmada entübasyon sonrası supin dönem, insuflasyon dönemi ve desuflasyon dönemi kompliyans değerleri ve postoperatif derlenme dönemi $\mathrm{PaO}_{2}$ değerleri BKV grubunda daha yüksek, desuflasyon dönemi $\mathrm{Vd} / \mathrm{Vt}$ ve $\mathrm{P}(\mathrm{A}-\mathrm{a}) \mathrm{O}_{2}$ değerleri ise düşüktü. Tüm dönemlerdeki kompliyans değerlerinin BKV modunda daha yüksek bulunması, bu moddaki gaz dağılımına bağlı olarak, azalan akım paterninin pulmoner gerilimi azaltmasına bağlıdır. Postoperatif $\mathrm{PaO}_{2}$ değerlerinin BKV grubunda yüksek bulunması, azalan akım paterni ve inspiratuvar akım hızının daha fazla olması, kısa zaman sabiteli alveollerin aşırı şişmesine neden olur. Daha sonra oluşturulan bu tidal volüm, ventile olan alveollerde daha homojen dağılım yaparak alveollerde rekruitment oluşturur ve atelektazi gelişimini engeller. Ayrıca VKV modunda tüm inspiratuvar plato zamanında akım sıfırlanırken, BKV modunda inspiryum sonunda inspiratuvar akım çok azalsa da sıfır olmaz. Bu da atelektazi gelişmesini engelleyen önemli bir faktördür. Tüm bu özellikler BKV grubunda ölü boşluk ve şant gelişiminin daha az olmasını da açıklamaktadır.

Sonuç olarak; laparoskopik kolesistektomi operasyonları sırasında oluşturulan pnömoperitonyumun oluşturacağı yan etkileri engellemede basınç kontrollü ventilasyon modunun, volüm kontrollü ventilasyon moduna alternatif olabileceğini düşünmekteyiz.

\section{Kaynaklar}

1. Peters JH, Ellison EC, Innes JT, et al. Safety and efficacy of laparoscopic cholecystectomy. Am Surg 1991;1:3-12.

2. Johnson $D$, Litwin $D$, Osachoff J, et al. Respiratory function after laparoscopic cholesistectomy. Surg Laparosc Endosc 1992;2:221-6.

3. Marco AP, Yeo CJ, Rock P. Anesthesia for patient undergoing laparoscopik cholecystectomy. Anesthesiology 1990;73:1268-70.

4. Cunningam AJ, Brul SJ. Laparoscopic cholecystectomy; anesthetic implications. Anesth Analg 1993;76:1120-33.

5. Al-Saady $N$, Bennett ED. Decelerating inspiratory flow waveform improves lung mechanics and gas exchage in patients on intermittent positive-pressure ventilation. Intensive Care Med 1985;11:68-75.

6. Campbell RS, Davis BR. Pressure-controlled versus volumecontrolled ventilation; what is matter? Respir Care 2002;47:416-24.

7. Markström AM, Lichtwarck-Aschoff $M$, Svensson BA, Nordgren KA, Sjöstrand UH. Ventilation with constant versus decelarating inspiratory flow in experimentally induced acute respiratory failure. Anesthesiology 1996;84:882-9.

8. Marini JJ, Ravenscraft SA. Mean airway pressure; physiologic determinants and clinical importance-part 2: Clinical implications. Crit Care Med 1992;20:1604-16.

9. Tyagi A, Kumar R, Sethi AK, Mohta M. A comparison of pressure-controlled and volume-controlled ventilation for laparoscopic cholecystectomy. Anaesthesia 2011;66:503-8.

10. Gupta SD, Kundu SB, Ghose T, et al. A comparison between volume-controlled ventilation and pressure-controlled ventilation in providing better oxygenation in obese patients undergoing laparoscopic cholecystectomy. Indian J Anaesth 2012;56:276-82.

11. Balick-Weber CC, Nicolas P, Hedreville-Montout M, Blanchet $P$, Stéphan F. Respiratory and haemodynamic effects of volume-controlled vs pressure-controlled ventilation during laparoscopy: a cross-over study with echocardiographic assessment. Br J Anaesth 2007;99:429-35.

12. Oğurlu M, Kucuk M, Sızlan A. Pressure-controlled vs volumecontrolled ventilation during laparoscopic gynecologic surgery. J Minim Invasive Gynecol 2010;17:295-300. 